\title{
Prospects for the sustainability of delivering the Basic Package of Health Services in Afghanistan: a stakeholder analysis
}

A.M. Haidari, ${ }^{1}$ S. Zaidi² ${ }^{\text {and R. Gul }}{ }^{3}$

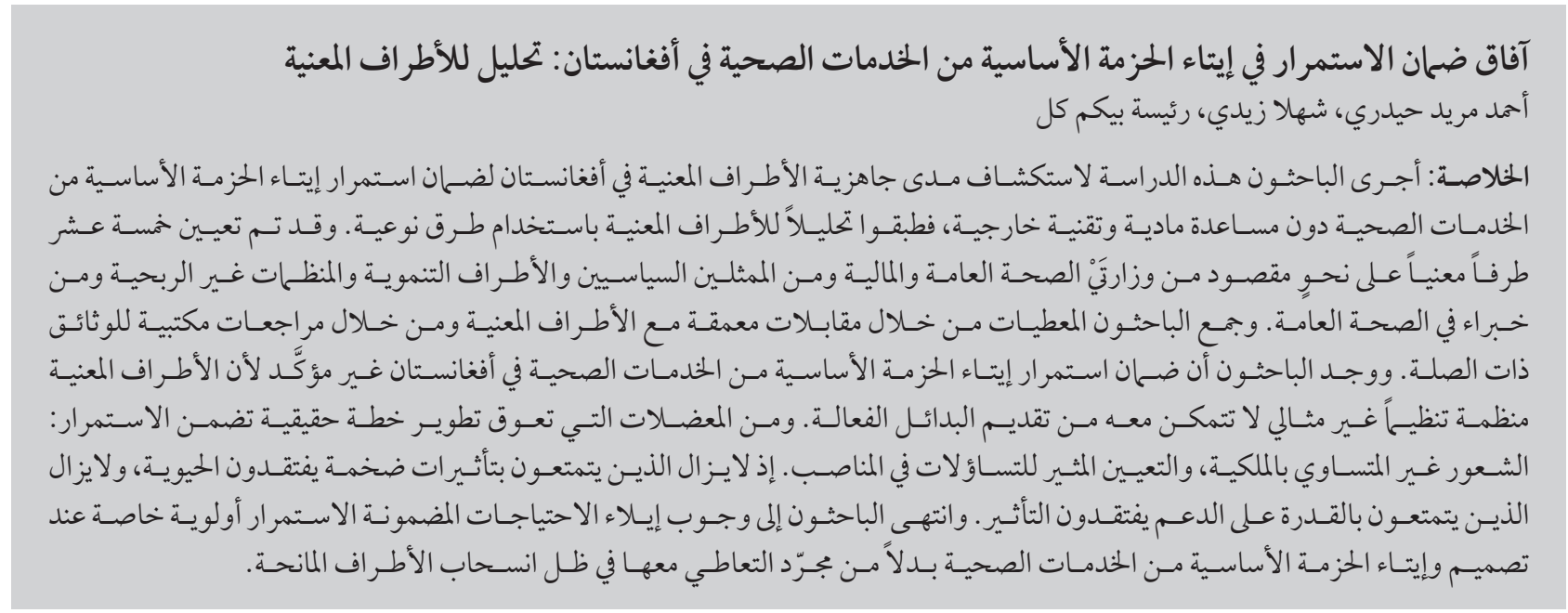

ABSTRACT This study explored the readiness of stakeholders in Afghanistan for sustaining delivery of the Basic Package of Health Services (BPHS) without external technical and financial assistance. A stakeholder analysis was applied using qualitative methods. Fifteen stakeholders were purposively drawn from the Afghanistan ministries of public health and finance, political representatives, development partners, nonprofit organizations and public health experts. Data were collected through in-depth interviews with the stakeholders and desk review of pertinent documents. We found that sustainability of the BPHS in Afghanistan is questionable as stakeholders are suboptimally organized to come up with effective alternatives. Uneven ownership and divisive positioning are bottlenecks to the evolution of a realistic continuation plan. Those with the most significant influence are lukewarm, while those who are most supportive have the least influence. Sustainability needs to be tackled at the start in designing the BPHS rather than in the wake of eventual donor withdrawal.

\section{Possibilités de pérennisation d'un ensemble de services de santé de base en Afghanistan : analyse des parties prenantes}

RÉSUMÉ La présente étude a été menée pour étudier l'état de préparation des parties prenantes en Afghanistan vis-à-vis de la pérennisation de l'ensemble de services de santé de base sans assistance technique ni financière extérieure. Une analyse des parties prenantes a été réalisée à l'aide de méthodes quantitatives. Quinze parties prenantes ont été choisies à dessein au ministère de la Santé publique, au ministère des Finances, dans des organismes à but non lucratif et parmi les représentants politiques, les partenaires de développement et les experts en santé publique en Afghanistan. Les données ont été recueillies dans le cadre d'entretiens approfondis avec les parties prenantes et d'une analyse documentaire des dossiers pertinents. Nous avons découvert que la pérennité de l'ensemble de services de santé de base en Afghanistan était problématique car les parties prenantes n'étaient pas organisées de manière optimale pour trouver des solutions alternatives efficaces. Une appropriation inégale et des prises de position discordantes sont des obstacles à l'évolution d'un plan de continuité réaliste. Les parties prenantes ayant le plus d'influence restent timorées, tandis que celles qui apportent le plus de soutien sont celles qui ont le moins d'influence. La question de la pérennité doit être traitée dès le début au moment de l'élaboration de l'ensemble de services de santé de base plutôt qu'après la menace du retrait du soutien d'un donateur.

${ }^{7}$ Ghazanfar Institute of Health Sciences, Ministry of Public Health, Kabul, Afghanistan (Correspondence to A.M. Haidari: haidari99@hotmail.com). ${ }^{2}$ Department of Community Health Science, Women and Child Health Division; ${ }^{3}$ School of Nursing, Aga Khan University, Karachi, Pakistan. Received: 04/11/12; accepted: 25/09/13 


\section{Introduction}

Sustainability in public health initiatives is often neglected $[1,2]$. Experience from Africa shows a decline in healthcare financing and services after withdrawal of external donor support $[3,4]$, while a study of the sustainability of immunization programmes in 50 lowand medium-income countries showed poor prospects for continuation and a need for early development of strategies to improve the reliability of financing [5]. However, the issue of sustainability is usually raised at the termination phase of external financing of health programmes rather than at an earlier stage.

After more than two decades of internal warfare which left a damaged health-care system, Afghanistan set up the Basic Package of Health Services (BPHS) in 2003 to roll out standardized services through frontline health facilities. The BPHS was designed, financed and technically supported by external donors and United $\mathrm{Na}$ tions agencies [6] and implemented through contracting-out to national and international nonprofit organizations
(NPOs) and contracting-in arrangements within the Afghanistan Ministry of Public Health (MoPH). The BPHS aims to standardize the health system as well as to improve equitable access to a minimum package of health services at 4 levels: the health post, the basic health centre, the comprehensive health centre and the district hospital, and more recently health subcentres and mobile health teams [7]. The BPHS is funded by three major donors - the United States Agency for International Development, the World Bank and the European Commission (Table 1) - whose contribution to the BPHS are estimated at $37 \%, 32 \%$ and $29 \%$ respectively [8], with the remaining small proportion from other donors and a negligible contribution from MoPH. Nevertheless, despite the huge contribution of external donors to the health sector, donors make up only $16.4 \%$ of total health expenditure [9]. Afghanistan has no provision for social or private health insurance and as a result there is significant out-of-pocket expenditure on health care by the population. Meanwhile, households in Afghanistan must fund the greatest proportion of the health care costs. Out-of-pocket expenditure is estimated as $75 \%$ of total health expenditure [10].

The results that are emerging from the BPHS are indicative of improved health outcomes, with reduction in the infant mortality rate [11], and coverage for $62 \%$ of the poorest population [12] through 1526 primary health-care centres [7]. However, as yet, neither donors nor recipients have a strategy worked out for continuation of the BPHS in case of a decline in donor funding [13]. This paper reports a stakeholder analysis that was conducted to examine the prospects for continuation of delivery of the BPHS, with the goal of providing informed decision-making about developing an exit strategy for donors. The aim was to identify the stands and political positions of stakeholders on the decision-making process in order to develop a sustainable strategy for continuation of the BPHS with reliance on as yet unmobilized resources.

\section{Methods}

\section{Study design}

A qualitative descriptive design [14] using Schmeer's framework for

Table 1 Unit per capita cost (US\$) and population covered by donors for the Afghanistan Basic Package of Health Services 2005-2009

\begin{tabular}{|c|c|c|c|c|c|}
\hline \multirow[t]{2}{*}{ Donor/variable } & \multicolumn{5}{|c|}{ Year } \\
\hline & 2005 & 2006 & 2007 & 2008 & 2009 \\
\hline \multicolumn{6}{|c|}{ USAID (13 provinces) } \\
\hline Population & 12037700 & 12298100 & 12627100 & 12912300 & 13204600 \\
\hline Cost & 4.0 & 1.6 & 1.8 & 1.9 & 1.5 \\
\hline \multicolumn{6}{|c|}{ World Bank (8 provinces) } \\
\hline Population & 4149500 & 4238600 & 4298800 & 4377000 & 4456500 \\
\hline Cost & 2.2 & 6.2 & 5.3 & 6.1 & 3.7 \\
\hline \multicolumn{6}{|c|}{$\begin{array}{l}\text { World Bank (3 provinces, } \\
\text { Strengthening Mechanism }\end{array}$} \\
\hline Population & 1065700 & 1088900 & 1100000 & 1119300 & 1138600 \\
\hline Cost & 2.1 & 7.0 & 4.1 & 3.6 & 4.1 \\
\hline \multicolumn{6}{|c|}{$\begin{array}{l}\text { European Commission (10 } \\
\text { provinces) }\end{array}$} \\
\hline Population & 4587400 & 4487800 & 4546000 & 4627600 & 4710800 \\
\hline Cost & 6.3 & 7.3 & 5.7 & 5.4 & 4.4 \\
\hline
\end{tabular}

USAID = United States Agency for International Development. 
stakeholder analysis [15] was used to address the study aims. Stakeholder analysis is a tool used to examine the feasibility of future policy directions, or to develop strategies to manage important stakeholders $[16,17]$. The analysis used in this study involved identification of key stakeholders and exploration of their interest in sustainability of the BPHS, their power and authority for action, their position taken on BPHS sustainability and the impact of a decline in donor funding on the stakeholders [18].

The definitions of the stakeholders' domains were adapted for this study as follows: "Interest" was defined as the degree of importance that the stakeholders gave to the continuation of the BPHS. "Power" was interpreted as the ability of stakeholders to introduce strategies for the BPHS, and helps to understand and address the concerns of stakeholders. "Position" was taken as a supporting, opposing or neutral stance adopted by stakeholders towards continuation of the BPHS in its present form, as well as the extent to which stakeholders are mobilized towards developing a way forward. "Impact" was interpreted as the consequences of the BPHS reform or continuation or scaling down on the different actors. A detailed explanation of each domain defined by Schmeer [15] is shown in Table 2.

\section{Sample}

The BPHS implementation system in Afghanistan is structured by its stakeholders: the MoPH, NPOs, donors/development partners, the Ministry of Finance $(\mathrm{MoF})$, politicians and the community. The MoPH contractsout the BPHS to NPOs; the donors are a financing source; the MoF is partially a financing agent and financing source to the BPHS; the politicians approve the health policies and strategies for the BPHS; and the community are the clients/users of the BPHS services.

A combination of purposive and snowball techniques were used to obtain the sample of stakeholders [19]. A preliminary list of stakeholders who had an interest in the BPHS and who played key roles in the policy- and decisionmaking, fund allocation, monitoring, financing, implementation and consumption of the BPHS services was prepared. From this list, a diverse group of stakeholders with rich information about the BPHS financing were selected for participation from the $\mathrm{MoPH}, \mathrm{MoF}$, the Afghanistan Parliament, donor and technical cooperation agencies, and national and international nongovernmental organization. Some of those participants helped to identify other stakeholders pertinent to the study.

\section{Data collection}

The data collection took place between July and September 2010. Data were collected through in-depth interviews with 15 stakeholders and a desk review of the documents related to the BPHS.

\section{Document review}

A document checklist was developed listing the policies and strategies, such as allocation formulae, donor exit strategies, health financing policy and strategies, and these were reviewed. Then other relevant documents available from stakeholders, such as annual budget decrees, donor financial reports, the BPHS contracts and "memorandums of understanding" between $\mathrm{MoPH}$ and donors were collected during and after the interviews. These documents were critically reviewed and analysed.

\section{Interviews}

The appointments for the interviews were arranged with the participants using email and phone calls. Each interview lasted approximately 40-60 minutes, and all interviews took place at the participant's office, except for the community representative who was interviewed at his house. The interviews were guided by a semi-structured interview guide with questions relevant to each domain of the stakeholder analysis framework. The languages used for interviews were English, Dari or Pashto. The interviews were tape-recorded and transcribed verbatim and then translated into English; the transcripts were verified with the tapes and analysed manually. Themes were developed using directed content analysis of data that was structured by four domains of the stakeholder analysis framework [20-23]. Then the stakeholders' roles

\begin{tabular}{|c|c|}
\hline Domain & Definition and rating \\
\hline Interest & $\begin{array}{l}\text { The degree of importance that the stakeholder gives to the issue helps the policy-maker to } \\
\text { understand the stakeholder and address his/her concerns. A general conclusion is drawn } \\
\text { based on the expressions of the stakeholder. Graded as low, medium or high }\end{array}$ \\
\hline Power \& authority & $\begin{array}{l}\text { The ability of stakeholder to affect the implementation of reform policy. This is analysed based } \\
\text { on the quantity of resources and ability of the stakeholders to mobilize his/her resources for } \\
\text { and against the policy. Graded as low, medium or high }\end{array}$ \\
\hline Position & $\begin{array}{l}\text { Whether the stakeholder expresses support, opposition or neutrality about the policy in } \\
\text { question. Graded as supportive, neutral or opponent }\end{array}$ \\
\hline Impact on stakeholder & $\begin{array}{l}\text { Shows the extent to which the policy in question will impact the stakeholder, if implemented. } \\
\text { Graded as low, medium or high }\end{array}$ \\
\hline
\end{tabular}

Source: Schmeer K [15]. 
in each domain were rated according to the thematic analysis. The stakeholders in this study were rated for the each domain by one principal rater and then reviewed by two other raters [23].

\section{Rigour}

A number of measures were taken to enhance the trustworthiness of the data [24]. Interview data from various stakeholders was triangulated $[25,26]$ with a desk review of the pertinent documents. Figures and financing data from documents were substantiated with information provided by participants. The interview guide and document checklist were pilot tested with MoPH staff to ensure the clarity of the questions. To allow free expression of their thoughts and feelings, participants selected the language of the interview. Conducting interviews in an appropriate language (local or English) and making field notes on the non-verbal cues of the participants strengthened the credibility of the data [27]. Interviews were transcribed by the principal investigator, who had good command of the local and English languages. The translated version of interview transcripts was verified by the participants to ensure the accuracy of the data. The transcripts were read and reread before analysis. Guidance was sought on the data analysis from experienced members of the team [28].

\section{Ethical considerations}

Ethical approvals were obtained from the ethics review board of the implementing research institution and institutional review board of the Afghan $\mathrm{MoPH}$. Written consent was obtained from participants.

\section{Results}

Analyses of the data are presented under the four domains, accompanied by a summary table in which stakeholders' roles are ranked (Table 3 ). To preserve anonymity of the participants, the anecdotes used in this section are not referenced with the participants' name, but with an abbreviation of the category to which they belong to followed by a numeric to indicate the sequence of interviews conducted at the time of data collection.

\section{Stakeholders' interest}

Interest was interpreted as the potential advantages and disadvantages that the continuation of the BPHS presented to the stakeholders [15].

The MoPH had a high level of interest and had developed the National Policy and Strategy on Healthcare Financing and Sustainability, 2009-2013, in which different financing mechanisms were strategized. For example, in view of its sustainability, the cost of the programme was kept at minimum, as an ex-official from the MoPH who was interviewed as a community representative (CR) described: "At the time of the BPHS costing, we estimated it US\$ 4.5 per person per year which was the lowest cost ... just for the sake of sustainability, thus in the future the Government of Afghanistan would be able to afford it." (CR\#05)

NPOs were moderately interested in continuation of the BPHS and related this to the good results they had achieved on the ground as contractors of services considering the example in the "Stakeholders' position" section of this paper (see later), but they pointed out bottlenecks that reduced their interest in continuation of the BPHS: "We had cost sharing till 2007 and the people were happy to pay an amount of money ... this money was able to manage, in some cases, the entire expenditure of facility for the time there was a gap in receiving funds from the donor, but it was stopped by government." (NPO \#07)

Interest among politicians (PT) was low and the continuation of the BPHS did not figure yet on the political agenda. They were not fully aware of the magnitude of external dependency and the reliance on limited resources for continuation of the BPHS, given the widespread poverty in the country. For example: "If the guidelines are made [by $\mathrm{MoPH}]$, we will agree on a transparent way for certain services particularly for laboratory and diagnostic equipment, whereas they [users] should pay lesser amount of money than market." (PT \#12)

Development partners (DP) also showed low interest in the issue and

\begin{tabular}{|c|c|c|c|c|c|}
\hline Stakeholder & Nature of involvement & Interest & $\begin{array}{l}\text { Power \& } \\
\text { authority }\end{array}$ & Position & $\begin{array}{l}\text { Impact on } \\
\text { stakeholder }\end{array}$ \\
\hline Ministry of Public Health & $\begin{array}{l}\text { Programme approval \& } \\
\text { implementation }\end{array}$ & High & Low & Very supportive & Medium \\
\hline Ministry of Finance & Fund allocation & Indifferent & High & Neutral (non-mobilized) & Low \\
\hline Politicians & Policy support & Low & Medium & Supportive & High \\
\hline Development partners & $\begin{array}{l}\text { Technical and financial } \\
\text { assistance }\end{array}$ & Low & $\begin{array}{l}\text { Medium } \\
\text { to high }\end{array}$ & Neutral (non-mobilized) & Low \\
\hline Non-profit organizations & $\begin{array}{l}\text { Contracted providers for } \\
\text { implementation }\end{array}$ & Medium & Low & Supportive & High \\
\hline Community & Service recipients & High & Low & Supportive & High \\
\hline
\end{tabular}


had contradictory opinions on the continuation of the BPHS as reflected in the following: "I have to say that this is a condition [dependency on donors] that donors themselves created for the health sector." (DP \#03)

The MoF was largely indifferent, having the view that this was an issue that the MoPH needed to tackle by working out different options for continuation of the BPHS and ignoring that the MoF plays a major role as a main source of funding. As one official from the MoF asserted when asked how the BPHS could be continued: "The MoPH should work on an overall strategy. I also ask those [MoPH officials] your question." (MoF\#08)

While in response to another question the participant reflected: "Indicating the prioritization is done by a budget committee that we $[\mathrm{MoF}]$ have. They indicate what percentage should go to health." (MoF\#08)

\section{Stakeholders' power and authority}

Power was defined as the ability of stakeholders to affect the continuation of the BPHS. It is based on the available resources and abilities being utilized for and against the initiative [15].

Despite its leadership role in the health sector and interest in continuation of the BPHS, the MoPH had low power on the issue because it was felt that the purse-strings were held by development partners and $\mathrm{MoF}$.

The MoF in its position as the revenue collection and resource allocation body had the highest power in mobilizing resources towards continuation of the BPHS. The thinking within MoF was that if the MoPH can prioritize its key areas for continued support then re-alignment of funds from other sources can be explored. As a representative from MoF expressed: "If they [the $\mathrm{MoPH}$ ] can prioritize their programmes, then we can provide them with few more funds in the budget even if there is a pressure." $(\mathrm{MoF} \# 08)$
"Pressure" here means the political pressure the participant experienced to allocate the fund to other sectors.

Developmentpartners (DP) also exerted considerable power on the BPHS sustainability. Their power stemmed from being the major financiers of the BPHS and managers of contracting for the BPHS: roles that may be complex for government to manage alone. Donors conceded that the design of the BPHS was such that it relied heavily on external support and would continue to do so even in the event of scaling down of funding: "We contract directly to NPOs ... in case we decide tomorrow to stop funding, it is not very easy to find such a bulk of money like an easy task to do." (DP\#01)

Politicians had considerable power to influence the mechanisms needed for continuation of the BPHS. The following comment by politician is consistent with others' reflections on user fees as a mechanism for the BPHS: "In the past, the user fee matter was rejected, because the Afghanistan Parliament had and currently has this view that user fee should not be encouraged until there are no principles and regulations formulated." (PT \#12)

NPOs, which comprised large international NPOs and a few local NPOs, were involved primarily as service contractors and as such had a weak political voice within the community to lobby for continued support for the BPHS. They were felt to carry some influence, however, among development partners, based on their performance achievement with contracts. Concerns were expressed by NPOs that additional funds over and above those proved to the BPHS by the government-managed contracting-in model might be superior to the NPOs, thereby limiting their role. "The SM [Strengthening Mechanisms] receive additional financial and technical support, from donor agencies. The donors $\mathrm{A} \mathrm{B}$, and especially $\mathrm{C}$, are in favour of SM projects and want to prove that the government provides better services. And they invest additional funds to support SM other than other the BPHS contractors." (NPO \#07)

\section{Stakeholders' position}

Position was defined as the degree of support, opposition or neutrality to continuation of the BPHS [15].

The MoPH was largely supportive of continuation of the BPHS but with introduction of new financing modalities involving both a greater degree of government support as well as cost recovery from the community. Thinking was still at an exploratory level, and had started with development of the national health policy and strategy, which had community financing pilots built in as a step towards sustainability [29]. Piloting on community insurance had already launched in five provinces [12], despite the constitutional stipulation concerning free health services for all citizens [30]. The need for evidence on community health funding, user fees and other community-based mechanisms was raised and there was recognition that strategy dialogue needed to be started with higher government entities, as one participant reflected: "We are in the way to start negotiation with the government, the Ministry of Finance, and also we strategized to examine the new schemes of health care financing such as community health funds, user fee ... taxation etc." (MoPH \#02)

Likewise, another participant asserted: "Most probably we would examine a combination of all options rather than going to for example funding by Government of Afghanistan or donors alone." (MoPH \#01)

The MoF had a neutral (non-mobilized) stance, maintaining that no steps had been taken to strategize the initiative, and it was interpreted as a technical issue and suggested that it needed to rely on the MoPH rather than depending on increased allocation from the MoF: " ... the continuation of the BPHS is a technical matter...the technical 
and sectoral part relates to Ministry of Public Health itself." (MoF \#08)

Politician representatives supported continuation of the BPHS but with the use of government revenues and agree with a systematized cost recovery from the community. The Afghanistan Parliament's decision to remove the user fee was cited as an example of political sensitivities towards illogical community recovery schemes, and an inclination towards greater allocation on health and systematic community financial contributions: "There are some taxes to be collected from the agriculture and goods commerce ... In addition to that, if the insurance system is accustomed [to it], in this case also one can access good services." (PT \#12)

Expert opinion was also supportive of continuation of the BPHS but pointed out the need for a closer interaction of $\mathrm{MoPH}$ with higher government entities. As the participant reflected: "I can cooperate with $\mathrm{MoPH}$ in the formulation and establishment of the policies and strategies and new initiatives, and devise them, but it relates to how much they $[\mathrm{MoPH}]$ accept it, and it needs the power and closeness to them." (CR $\# 05$ )

Community representatives were in favour of the BPHS continuing at the existing subsidy level and were strongly opposed to a cost-recovery scheme. Low affordability due to the bleak economic scenario in the country was the argument given against cost-recovery from the community: "They [the people] cannot support it financially, because their economic status is already worsened and it is at zero in X [name of village]." (CR\#15)

Development partners felt that the BPHS should be continued, and pointed to human resource development and limited support for financing as potential contributions: "If there is health care financing process, we can help. And also we can help in human resources development." (DP \#06). "The
$X$ [name of agency] can work with the Ministry hand to hand." (DP\#11)

However, there had been little dialogue on moving towards a sustainable plan. NPOs were supportive of the BPHS continuation and expressed readiness to work with government in designing and implementation of pilots using new financing modalities: "We are ready to implement and take part in the [health care financing] pilot studies if they [MoPH officials] want it at the community level ... we also have the technical expertise to work with the government, to design and provide support in the study settings." (NPO\#07)

\section{Impact on stakeholders}

Impact was defined the consequences of modification of the BPHS on the different actors. It provides information on what would be the concerns of all stakeholders in case the BPHS was not supported [31]. A sudden exit of development partners was considered unlikely. However, eventual weaning from financial assistance was regarded with alarm by some and indifference by other stakeholders. The MoPH had apprehensions about the collapse of frontline health care with withdrawal of donor support but was cautiously optimistic about working out some level of maintenance support from external funds to continue the BPHS: +"I don't want to talk about sudden donor exit, which is not anticipated, but of course, if it [external assistance] suddenly stops, the system will collapse." (MoPH\#02)

The MoF counted the BPHS as one of the several competing development needs of Afghanistan. The MoF maintained that scaling down would probably be necessary for continuation of the BPHS. However, development needs were seen as more than just the BPHS and would continue to be contributed to by a number of sectors. "It does not mean that the projects will not be affected. The national budget and national priority is not health alone. There is also education. There is also security. There is also infrastructure." (MoF\#08)

Politicians and community representatives felt that reliance could not be placed on internal budgetary support and could lead to catastrophic expenditure by households, putting health out of reach of ordinary people: "With this much assistance that comes from abroad, we are in such condition [nothing is available in clinics], if these supports are even stopped, then what will happen, if they are not funding, as our people say everything will remain jaam [inert]" (CR\#15)

The NPOs also voiced concerns about the vulnerability of the system, pointing to shortfalls faced even with the existing BPHS contracts. There were apprehensions about not finding sufficient work in case of scaling down of the BPHS. Moreover, there were also apprehensions that with a declining role for donors, the BPHS financing would be invested more in governmentmanaged health care and comparatively less on health care contracted to NPOs.

In summary, we found that there was a high level of interest within the $\mathrm{MoPH}$ for continuation of the BPHS, which was reciprocated by NPOs and community. However, these stakeholders had low levels of policy influence on the BPHS continuing. The MoPH was also sufficiently mobilized, having introduced financing policy and piloted alternative financing. However, interest ranged from supportive to lukewarm among the MoF, politicians and donors and there was a clear lack of mobilization of these stakeholders despite significant power and influence on financing reform for the BPHS. Targeted efforts are needed to broaden interest and ownership in sustainability of the BPHS and to come up with a resource contribution plan and accompanying technical modifications. Sustainability needed to be tackled in advance in the design of the BPHS rather than after the eventual donor withdrawal. 


\section{Discussion}

Sustainability of donor-supported programmes is a cause for concern, but has not been extensively examined in public health research and therefore the evidence, where available, is largely based on quantitative aspects. Our study probed the qualitative dimensions of continuation of the BPHS in Afghanistan, focusing on financial sustainability in the face of a decline in donor support. We conducted an analysis to ascertain stakeholders' interest in the issue, their relative power and influence, their positions concerning future options and the impact on them. Published literature on Afghanistan has highlighted the importance of different stakeholders in shaping the BHPS and has cautioned about the challenges of sustainability [6]. The need for better understanding of the potential role that stakeholders can play in the BPHS continuation has also been raised [32]. We explored these concerns by looking into stakeholders' potential roles in continuation of the BPHS, and how stakeholders could be influenced to move forward.

The BPHS is almost totally reliant on external aid, and stakeholders are suboptimally organized to come up with effective alternatives. We found that although there was a high level of interest within the $\mathrm{MoPH}$ for continuation of the BPHS and a similar interest among the community, there was a varying level of interest among other stakeholders. There is a particular need to advocate for the BPHS continuation and sustainability options among politicians and the MoPH, who are the stakeholders with significant power and influence, but for whom the BPHS is not as yet a major issue. Moving beyond fostering ownership of this issue, there was also need identified for targeted efforts towards mobilization of stakeholders for concerted action. We found that only the MoPH was prepared, by having developed a five-year financing policy and a strategy backed by pilot studies of community prepayment. However, further efforts are needed to come up with a resource contribution plan and accompanying technical modifications to the BPHS. This will require mobilization of MoF, politicians and development partners and also require grounded evidence from community pilots. The findings also showed that development partners, despite recognizing the issue of problematic sustainability, have shelved the issues rather than working towards developing a workable phase-out strategy. The consequences of fund withdrawal have a bottom-up effect on the community and NPOs, but there is low influence of both these stakeholders on the policy processes.

Review of experience from other low- to medium-income countries argues that programme sustainability can be addressed through mobilizing additional resources, increasing the reliability of financing, and improving programme efficiency [5]. We found that mobilization of additional resources was the main issue that needed to be tackled in Afghanistan, but that this also could involve improving the efficiency of the programme through re-consideration of current implementation strategies. Revenue generation measures that were identified included spreading out the cost of the BPHS across government contributions, household recovery and some level of continued external donor support. Opinion was divided over the relative level of contributions among stakeholders and showed a need for a consensus strategy across all stakeholders. Matching contributions by donors may also be of value in maintaining government contributions into the BPHS. However, all stakeholders felt that, even with cost-sharing mechanisms put in place the BPHS would require considerable scaling down.

A study funded by the World Bank provided similar data about the overall situation of the health sector in
Afghanistan although it did not focus on the BPHS [33]. Recently, the issue of programme sustainability has been given more consideration in developing countries. An understanding of stakeholders plays an important role in bringing reforms that will enhance the continuation of the BPHS [32]. We therefore addressed an important point, which is detection of the stakeholders' potential roles and functions in the continuation of the BPHS, and how they can move the reforms forward.

In summary, Afghanistan is extremely reliant on external aid for implementation of the BPHS. Although sustainability mechanisms need to be introduced into health programming before donor exit, the stakeholder community is as yet poorly organized towards sustainability. Re-assessment of the sources of BHPS financing and of modifications to delivery are needed. The MoPH's health financing strategy is a good starting point; however, efforts towards improving ownership of the issue need to be directed towards other stakeholders in order to develop a consensus strategy. This would need to be followed with a clear time frame and action plan. Efficiency generation measures aimed at design, delivery and monitoring of BHPS were not considered in-depth in the study and this may be considered a weakness of the study. Efficiency measures may require re-examining the costs invested in the management of contracting and in the monitoring of the BPHS, with alternatives designed with a view to reducing transaction costs.

\section{Strengths and limitations}

Some of the strengths of the study were that it was conducted in a timely way to respond to the increasing attention of health policy-makers on the topic. Efforts were made to include a wide range of health sector stakeholders, in order to triangulate views. A systematic approach to interviews was followed, from inviting participants and establishing 
relationships with them, to completion of interviews, to analysis.

Some limitations of our study were that the stakeholders' ranking, which is a highly sophisticated tool designed to be performed by a group of experts, was applied by a single rater. To reduce individual bias, the principle rater's work was reviewed and modified by two secondary raters. Although the idea of focus group discussions was raised as a suitable approach to data collection, these could not be conducted due to feasibility issues. To tackle this issue, the data from community representatives and public health experts were grouped for analysis so that the experts could act as a voice for the community as well. However, focus group discussion might have generated richer results. During the interviews, one participant did not allow us to record his voice and another participant's voice was not recorded due to logistic issues. To resolve this issue, the field notes were used to transcribe the data immediately after interview and the transcribed data were checked by other team members.

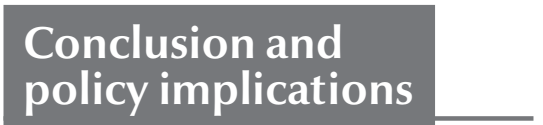

Although doubts have been raised about the continuation of the BPHS in Afghanistan, stakeholders are presently inadequately organized to tackle this issue. Uneven ownership and divisive views are potential bottlenecks to evolution of a realistic continuation plan.

The Government of Afghanistan's updated health care financing policy and strategy should be revisited and a clear time frame and action plan for piloting each intervention should be defined and moved forward. This can be strategized wisely by involving stakeholders in order to understand their interest, power and position towards the interventions and their impact on stakeholders. This paper can be used to inform this process.

Competing interests: None declared.

\section{References}

1. Schell SF et al. Public health programme capacity for sustainability: a new framework. Implementation Science, 2013, 8:15.

2. Monson SP et al. Working toward financial sustainability of integrated behavioral health services in a public health care system. Families, Systems and Health, 2012, 30(2):181-186.

3. Thomson $\mathrm{S}$ et al. Addressing financial sustainability in health systems. Policy brief 1. Geneva, World Health Organization, on behalf of the European Observatory on Health Systems and Policies, 2009.

4. Heller PS. The prospects of creating "fiscal space" for the health sector. Health Policy and Planning, 2006, 21(2):75-79.

5. Kamara L et al. Strategies for financial sustainability of immunization programs: a review of the strategies from 50 national immunization program financial sustainability plans. Vaccine, 2008, 26:6717-6726.

6. Sabri B et al. Towards sustainable delivery of health services in Afghanistan: options for the future. World Hospitals and Health Services, 2007, 43:10-16.

7. A Basic Package of Health Services for Afghanistan, 2005/1384. Kabul, Afghanistan Ministry of Public Health (http:// moph.gov.af/Content/Media/Documents/BPHS-2005-FINAL29122010162945969.pdf, accessed 23 January 2014).

8. Newbrander W, Yoder R, Debevoise AB. Rebuilding health systems in post-conflict countries: estimating the costs of basic services. International Journal of Health Planning and Management, 2007, 22:319-336.

9. Health financing: health expenditure ratios by country. Global Health Observatory Data Repository, World Health Organization [online database] (http://apps.who.int/gho/data/node. main.75?lang=en, accessed 23 January 2014).

10. Afghanistan national health accounts 2008-2009. Kabul, Afghanistan Ministry of Public Health, 2011 (http://www.who. int/nha/country/afg/afg-nha_2008-2009.pdf, accessed 23 January 2014).

11. Loevinsohn B, Sayed GD. Lessons from the health sector in Afghanistan: how progress can be made in challenging circumstances. Journal of the American Medical Association, 2008, 300(6): 724-726.
12. Rao KD et al. An experiment with community health funds in Afghanistan. Health Policy and Planning, 2009, 24:301-311.

13. Analysis: Afghan health NGOs-a mixed blessing? IRIN [online] (http://www.irinnews.org/Report.aspx?Reportld=86542, accessed 23 January 2014).

14. Sandelowski M. What's in a name? Qualitative description revisited. Research in Nursing and Health, 2010, 33(1):77-84.

15. Schmeer K. Section 2. Stakeholder analysis guidelines. In: Policy toolkit for strengthening health sector reform. Geneva, World Health Organization, 1999 (http://www.who.int/workforcealliance/knowledge/toolkit/33.pdf, accessed 23 January 2014).

16. Baum KD et al. Implementing change in health professions education: stakeholder analysis and coalition building. Journal of Veterinary Medical Education, 2007, 34(2):79-84.

17. Stefl ME, Tucker SL. Applying stakeholder analysis to health care administration education. Journal of Health Administration Education, 1994, 12(2):119-144.

18. Brugha R, Varvasovszky Z. Stakeholder analysis: a review. Health Policy and Planning, 2000, 15(3):239-246.

19. Hanson JL, Balmer DF, Giardino AP. Qualitative research methods for medical educators. Academic Pediatrics, 2011, 11(5):375-386.

20. Seidel JV. Qualitative data analysis. Colorado Springs, Colorado, Qualis Research, 1998.

21. Hsieh HF, Shannon SE. Three approaches to qualitative content analysis. Qualitative Health Research, 2005, 15(9):1277-1288.

22. Vaismoradi M, Turunen $\mathrm{H}$, Bondas T. Content analysis and thematic analysis: Implications for conducting a qualitative descriptive study. Nursing and Health Sciences, 2013, 15(3):398-405.

23. Pope C, Ziebland S, Mays N. Qualitative research in health care. Analysing qualitative data. British Medical Journal, 2000, 320:114-116.

24. Williams EN, Morrow SL. Achieving trustworthiness in qualitative research: a pan-paradigmatic perspective. Psychotherapy Research, 2009, 19:576-582.

25. Law M et al. Guidelines for critical review form-qualitative studies. Hamilton, Ontario, McMaster University Occupational 
Therapy Evidence-Based Practice Research Group (http:// www.srs-mcmaster.ca/Portals/20/pdf/ebp/qualguidelines_ version2.0.pdf, accessed 23 January 2014).

26. Sharts-Hopko NC. Assessing rigor in qualitative research. Journal of the Association of Nurses in AIDS Care, 2002, 13:84-86.

27. Begley CM. Triangulation of communication skills in qualitative research instruments. Journal of Advanced Nursing, 1996, 24:688-693.

28. Sandelowski M. Rigor or rigor mortis: the problem of rigor in qualitative research revisited. Advances in Nursing Science, 1993, 16:1-8.

29. Strong L, Wali A, Sondorp E, eds. Health policy in Afghanistan: two years of rapid change. A review of the process from 2001 to 2003. London, London School of Hygiene and Tropical Medicine, 2005 (http://crises.Ishtm.ac.uk/files/2008/10/ Health-Policy-in-Afghanistan-two-years-of-rapid-change.pdf, accessed 23 January 2014).
30. Constitution of the Islamic Republic of Afghanistan. ICL document status: 26 Jan 2004 (http://www.servat.unibe.ch/icl/ af00000_.html, accessed 23 January 2014).

31. What is stakeholder analysis? Washington DC, World Bank, 2010 (http://www1.worldbank.org/publicsector/anticorrupt/ PoliticalEconomy/PDFVersion.pdf, accessed 23 January 2014).

32. Ridde V, Pluye P, Queuille L. Évaluer la pérennité des programmes de santé publique : un outil et son application en Haïti. [Assessing programme sustainability in public health organizations: a tool-kit application in Haiti]. Revue d'Epidémiologie et de Santé Publique, 2006, 54(5):421-431.

33. Belay TA, ed. Building on early gains in Afghanistan's health, nutrition, and population sector: challenges and options. Washington DC, World Bank, 2010 (http://www-wds.worldbank.org/ external/default/WDSContentServer/WDSP/IB/2010/06/04 /000333037_20100604020800/Rendered/PDF/548950PU B0EPI11C10Dislosed061312010.pdf, accessed 23 January 2014). 